\title{
Cephalosporin-induced recurrent aplastic anemia
}

\author{
Jimin Han • Hyojeong Lee $\cdot$ Yoon Su Lee \\ Yun-Jeong Bae • You Sook Cho • Hee-Bom Moon • \\ Tae-Bum Kim
}

Received: 3 August 2010 / Accepted: 24 September 2010/Published online: 12 October 2010

(C) The Author(s) 2010. This article is published with open access at Springerlink.com

Cephalosporins are antibiotics widely used to treat infections in the skin, soft tissues, and respiratory and urinary tracts. Aplastic anemia (AA) has not previously been reported in patients treated with cephalosporins. We describe here a 50year-old woman who experienced AA after treatment with cefroxadine.

In November 2009, a 50-year-old woman was referred to our medical center for further treatment of AA. In October 2009, the patient had received a 3-day course of cefroxadine, non-steroidal anti-inflammatory drugs (NSAIDs), and antihistamines to treat symptoms of a common cold. The symptoms were relieved, but 1 week after treatment she developed a fever and sore throat. The patient visited a primary clinic, where a blood examination showed evidence of neutropenia. The patient had taken no other medications in the 6 months prior to the illness and had no underlying disease.

Physical examination showed oropharyngeal injection and soft palate swelling. Her hemoglobin $(\mathrm{Hb})$ level was $9.9 \mathrm{~g} / \mathrm{dL}$, WBC count was $300 / \mathrm{mm}^{3}$, with $3.1 \%$ neutrophils (absolute neutrophil count $10 / \mathrm{mm}^{3}$ ), and platelet count was $34,000 / \mathrm{mm}^{3}$. A marrow aspirate revealed severe hypoplasia, with almost complete disappearance of cells of the granulocytic and megakaryocytic lineages, and few cells of the erythroid lineage. A marrow biopsy showed severe AA ( $15 \%$ cellularity), affecting all hematopoietic lineages (Fig. 1). She was treated supportively with broad-spectrum antibiotics (meropenem)

J. Han $\cdot$ H. Lee $\cdot$ Y. S. Lee $\cdot$ Y.-J. Bae $\cdot$ Y. S. Cho $\cdot$ H.-B. Moon

T.-B. $\operatorname{Kim}(\bowtie)$

Division of Allergy and Clinical Immunology, Department of Internal Medicine, Asan Medical Center, University of Ulsan College of Medicine,

388-1 Pungnap-2dong, Songpa-gu,

Seoul 138-736, Korea

e-mail: allergy@medimail.co.kr and granulocyte macrophage colony-stimulating factor (GM-CSF). Her fever subsided on day 6, and she showed clinical improvement. Her $\mathrm{Hb}$ and $\mathrm{WBC}$ and platelet counts gradually increased. She was discharged on day 29 with a $\mathrm{Hb}$ concentration of $11.4 \mathrm{~g} / \mathrm{dL}$, a WBC count of $4.3 \times 10^{3} / \mu \mathrm{L}$ ( $73 \%$ neutrophils), and a platelet count of $102 \times 10^{3} / \mu \mathrm{L}$. One month later, her hemoglobin was $10.8 \mathrm{~g} / \mathrm{dL}$, WBC was $4,200 / \mathrm{mm}^{3}$ (52.4\% neutrophils), and platelet count was $107,000 / \mathrm{mm}^{3}$.

It is noteworthy that this was the patient's third incidence of drug-induced AA. She had a previous history of cefroxadine-induced recurrent AA, from which she had fully recovered after withdrawal of the medication. In December 2007, the patient had been referred to our medical center with laryngopharyngitis plus suppurative lymphadenitis and AA after taking an unknown drug 2 weeks previously. In April 2008, AA recurred after she took cefroxadine for URI medications. Initial bone marrow aspirations and biopsies taken after each incident revealed AA; 1 month after the incident, she had fully recovered from pancytopenia after conservative care. We guess that the drug in the first episode had probably been a cephalosporin. Cephalosporin was thus involved in at least 2 of the 3 episodes of AA.

Because of its rarity, the mechanism underlying cephalosporin-induced AA has not been completely determined. In contrast to agranulocytosis, which is probably caused by a humoral immune reaction against mature circulating lymphocytes, acquired AA is most likely caused by a humoral autoimmune reaction against myeloid stem cells. A T cell attack on bone marrow leads to the apoptosis of CD34+ cells, resulting in pancytopenia and symptoms of bone marrow failure [1,2].

A prospective cohort study of 102 patients with druginduced agranulocytosis over 15 years (1985-2000) found 
Fig. 1 Biopsy of bone marrow. Original magnification of $\mathbf{a}$ $\times 100$ and $\mathbf{b} \times 400, \mathrm{H} \& \mathrm{E}$ staining. It shows low cellularity $(15 \%)$ affecting all hematopoietic lineages
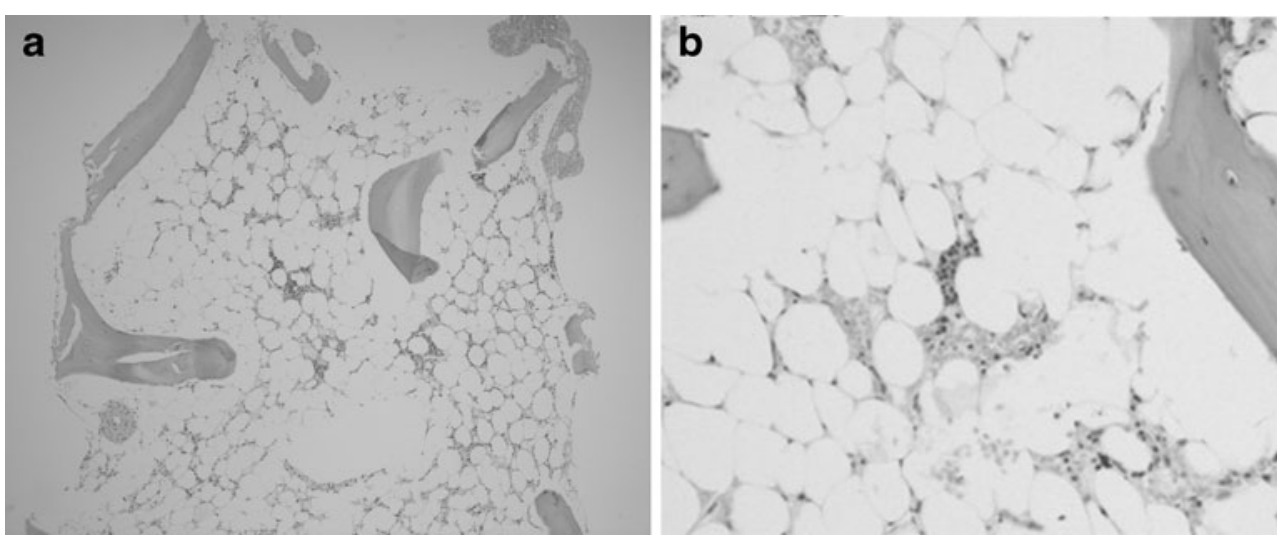

that 21 patients had antibiotic-induced agranulocytosis, including 4 patients with agranulocytosis due to a cephalosporin, 2 due to cefotaxime and 1 each due to ceftriaxone and ceftazidime [3]. Similarly, of 108 patients with agranulocytosis over the period 1987-1990, 75 had drug-related agranulocytosis [4]. None of these patients with agranulocytosis, however, developed AA. Administration of high doses of cephalosporin to dogs induced AA, with evidence of immune-mediated destruction of peripheral blood cells and marrow colony-forming capacity [5].

The development of AA in association with cefroxadine, a second-generation cephalosporin, has not previously been reported. Both the occurrence of AA after administration of cefroxadine and its spontaneous resolution within 15 weeks of drug discontinuation indicate that AA in this patient was probably caused by cefroxadine.

Prior to discharge, we performed an intradermal test with a gradual increase in concentration to determine whether this patient had an immediate type I hypersensitivity to cephalosporin. We found, however, that her recovered WBC decreased slightly for 1 week after the intradermal test and no immediate skin reaction occurred. The mechanism underlying this reaction is not certain, but it may be triggered weakly by intradermal injection of antigen (cephalosporin). The diagnostic relevance and the possible risks of the intradermal test in AA have not yet been established.

Cephalosporins are among the safest antibiotics. Nevertheless, hematological abnormalities, ranging from monocytopenia to pancytopenia, do occur, albeit infrequently, following their therapeutic use. Cefroxadine has become more widely used for simple infectious conditions in primary clinics. This case illustrates that a severe complication of antibiotic treatment may occur. Therefore, physicians should use antibiotics more restrictively only when they are necessary, provide care to patients taking the drug, and be aware of this potentially life-threatening complication.

Acknowledgement This research was supported by a grant (09182KFDA845) from the Korea Food \& Drug Administration in 2010.

Open Access This article is distributed under the terms of the Creative Commons Attribution Noncommercial License which permits any noncommercial use, distribution, and reproduction in any medium, provided the original author(s) and source are credited.

\section{References}

1. Young NS (2002) Acquired aplastic anemia. Ann Intern Med 136 (7):534-546

2. Young NS, Calado RT, Scheinberg P (2006) Current concepts in the pathophysiology and treatment of aplastic anemia. Blood 108 (8):2509-2519

3. Andres E, Maloisel F (2001) Antibiotic-induced agranulocytosis: a monocentric study of 21 cases. Arch Intern Med 161 (21):2619

4. Van der Klauw MM, Goudsmit R, Halie MR, van't Veer MB, Herings RM, Wilson JH, Stricker BH (1999) A population-based case-cohort study of drug-associated agranulocytosis. Arch Intern Med 159(4):369-374

5. Deldar A, Lewis H, Bloom J, Weiss L (1988) Cephalosporininduced alterations in erythroid (CFU-E) and granulocytemacrophage (CFU-GM) colony-forming capacity in canine bone marrow. Fundam Appl Toxicol 11(3):450-463 